\title{
How do low-abundance taxa affect river biomonitoring? Exploring the response of different macroinvertebrate-based indices
}

\author{
Simone GUARESCHI,${ }^{*}$ Alex LAINI, ${ }^{2}$ Maria M. SÁNCHEZ-MONTOYA ${ }^{1,3}$ \\ ${ }^{1}$ Department of Ecology and Hydrology, Regional Campus of International Importance "Campus Mare Nostrum", University of \\ Murcia, Espinardo Campus, 30100 Murcia, Spain; ${ }^{2}$ Department of Life Science, University of Parma, Viale G.P. Usberti 33/A, 43124 \\ Parma, Italy; ${ }^{3}$ Leibniz-Institute of Freshwater Ecology and Inland Fisheries (IGB), Müggelseedamm 310, 12587 Berlin, Germany \\ *Corresponding author: simone.guareschi@um.es
}

\begin{abstract}
The contribution of rare taxa to aquatic bioassessments remains a subject of debate, and generates contrasting positions among researchers. Very little is known about the effect of low-abundance taxa (LAT) for calculating both single and multimetric macroinvertebrate-based indices, as well as the ecological status classification. In this study, we aimed to: i) identify the aquatic macroinvertebrates that need special attention during index applications given their low abundance; ii) analyse the effect of excluding LAT on single (IBMWP and IASPT) and multimetric (STAR_ICMi) biological indices; and iii) investigate the influence of LAT on river ecological status assessments. To this end, two different river basins in SE Spain and N Italy with contrasting climatic conditions and river types were selected. Our results showed that almost all the taxa at the family level can act as low-abundance taxa. In particular, the LAT belonged mainly to Diptera, Trichoptera, Coleoptera, Gastropoda and Hemiptera. The IndVal analysis stressed Tabanidae, Cordulegasteridae and Hydroptilidae as the most characteristic low-abundance families in the Spanish data set, while Dryopidae and Athericidae were identified mostly in N Italy. Excluding LAT affected the studied index values and the resulting bioassessment classification, except for the IASPT index. Loss of the entire LAT pool reduced the ecological status for $78 \%$ of the samples for the IBMWP index. Changing took place in $41 \%$ of the samples when considering the STAR_ICM index. Relevant changes were detected even when considering loss of $50 \%$ of the LAT, especially with the IBMWP index. Similar values and patterns were obtained in each considered quality class and river type. Our results provide useful information about controversial taxa and stress the significance of LAT in river biomonitoring. Excluding LAT is discouraged, although different responses according to the considered index were detected. The IBMWP index always obtained lower values (coupled mainly with an underestimation of ecological classes), while STAR_ICMi and, especially the IASPT index, were less affected by excluding LAT. Paying special attention to all the protocol application stages is recommended, with emphasis placed when using the IBMWP index.
\end{abstract}

Key word: Bioassessment; rare taxa; ecological classes; IBMWP; IASPT; STAR_ICMi.

\section{INTRODUCTION}

River assessment is extensively based on aquatic macroinvertebrates and numerous biomonitoring indices have been developed for this purpose (Doledéc and Statzner, 2010; Birk et al., 2012; Bo et al., 2016). These indices are generally based on rapid biological assessment protocols (Barbour el al., 1999), followed to obtain a practical and rigorous assessment of river ecological conditions. However, macroinvertebrate sampling activities may reflect just one part of the community, and documenting some taxa (e.g., with either low abundances or small distribution ranges) is often time-consuming and cost-intensive in terms of fieldwork, laboratory work, data processing and analyses (Nijboer and Schmidt-Kloiber, 2004).

These taxa are generally called "rare" (Gaston 1994; Nijboer and Verdonschot, 2004) and their contribution to aquatic biomonitoring has received particular attention in multivariate analyses for bioassessment (Cao et al., 2001; Marchant 2002) and predictive methods, especially in
Anglo-Saxon countries (e.g., the RIVPACS approach; Clarke and Murphy, 2006; Van Sickle et al., 2007). Nevertheless, this debate is ongoing with researchers offering contrasting positions and findings (Cao and Williams, 1999; Marchant et al., 1999; Poos and Jackson, 2012). Very little is known about the effect of rare taxa for calculating single or multimetric macroinvertebrate-based indices or about the effect on ecological status assessments, especially in South Europe.

Contrary to taxa with small distribution ranges, lowabundance taxa (herein referred to as LAT) might be present in numerous samples, sites and habitats, but have the general peculiarity of presenting low number of individuals during sampling activities. Although excluding this kind of taxa may be cost-effective (especially in the field) when applying rapid biological assessment protocols, LAT may be common contributors to the assemblage structure in undisturbed streams (Robinson et al., 2000), and might even represent the largest overall richness component (Cao et al., 1998).

The low abundance of a macroinvertebrate taxon, or 
even its absence, from a sample can be attributed to both structural (i.e., an inhospitable environment that does not allow a species to establish) and stochastic (i.e., incomplete characterisation of a macroinvertebrate community) causes (Gray, 2005). In this study, we focused specially on this second aspect as community characterisation can be strictly related with difficulties during fieldwork or laboratory procedures, such as operator efficiency (Metzeling et al., 2003), sorting errors (Haase et al., 2010), or subsampling methods (Nichols and Norris, 2006). As a result, some methods and procedures may be biased towards large, abundant and widely distributed taxa (Gillies et al., 2009; Haase et al., 2010). LAT have fewer chances of being sampled, so their distribution range can be underestimated (Nijboer and Verdonschot, 2004). The imperfect detection of these taxa can be a common problem that may affect numerous biological metrics; for instance, total taxon richness and EPT richness, which are two of the main metrics used in biomonitoring (Birk et al., 2012).

In order to improve knowledge on this topic and to provide applied information and recommendations for environmental agencies, technicians and researchers, we aimed to: i) identify the aquatic macroinvertebrates that need special attention during biomonitoring (in different river types) given their potential low abundance; ii) analyse the effect of excluding LAT from the single (IBMWP and IASPT) and multimetric (STAR_ICMi) indices; and iii) test their influence on river ecological status assessments.

When addressing the first objective, we stressed those taxa that need special attention while applying protocols by discussing their ecological preferences and features. When dealing with the other two, we investigated whether the exclusion of these taxa could be considered crucial for determining not only the index final values, but also ecological classes, to provide useful information about effi- cient future sampling strategies or line guides. In this way, the comparison of different index outcomes and behaviours is possible and useful as study metrics and indices are among the most widely used tools in river bioassessments (Armitage et al., 1983; Munné and Prat, 2009; Laini et al., 2014; Buss et al., 2015). Finally, controversial issues and possible future implications are discussed.

\section{METHODS}

\section{Study area and sampling sites}

The present study was carried out by analysing different biogeographical and climatic regions (S Spain and N Italy). We focused on the Segura Basin (SE Spain, Fig. 1a) with 30 sites located in the Murcia, Andalusia and Castilla-la Mancha regions, which were sampled mainly during three seasons in 2000-2003 for 81 sample data (Supplementary Tab. 1). The Segura Basin is an environmentally diverse basin, considered a good candidate to be utilised as a Mediterranean pilot basin (Bruno et al., 2014). Agricultural impacts and dam regulation have been recognised as representing the most important pressures on aquatic ecosystems in this catchment (Kroll et al., 2013; Sánchez-Montoya et al., 2009; Bruno et al., 2014). We considered types, reference values and class boundary values according to those proposed by Sánchez-Montoya et al. $(2007,2010)$ and developed in the Spanish study area. These biological data and types were developed as part of the GUADALMED II Project for Mediterranean Spanish rivers (Prat, 2004). To obtain a representative data set, the sites of four of the five river types in Mediterranean rivers were considered (including temporary and perennial, and different lithologies; Tab. 1).

We also studied the effect of LAT on biomonitoring in the Po Basin (N Italy, Fig. 1b). It is the widest river basin

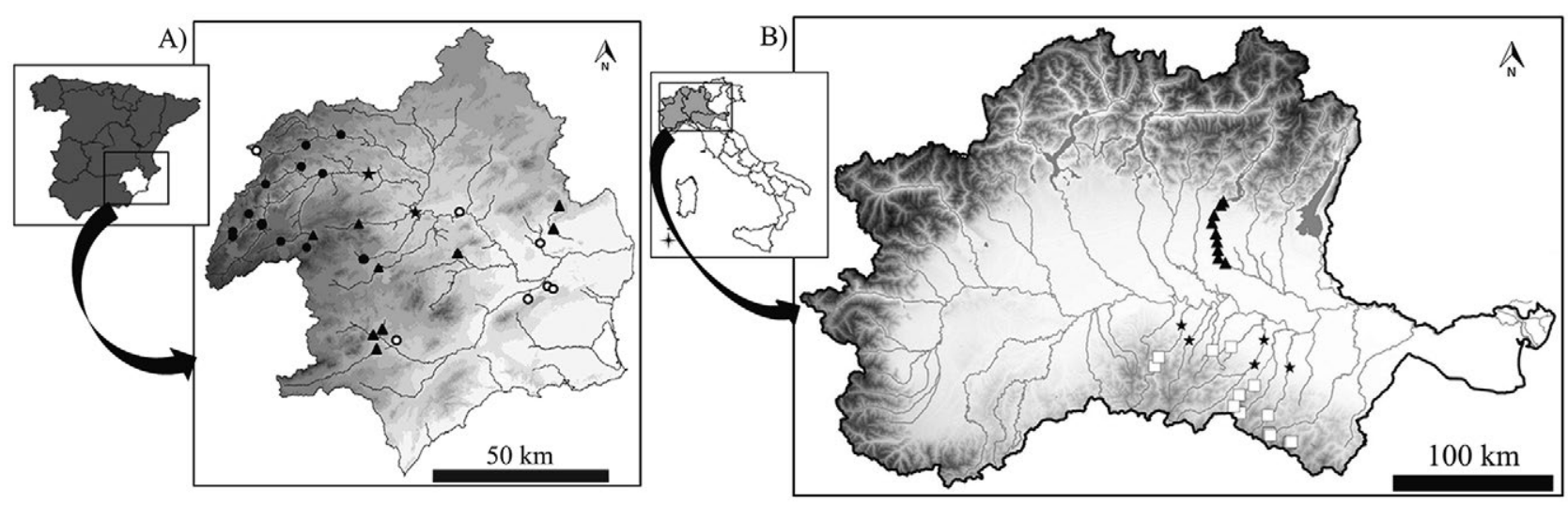

Fig. 1. Study area and location of sampling sites. A) Segura Basin (SE Spain; white circles, T1 sites; black triangles, T2 sites; black circles, T4 sites; black stars, T5 sites). B) Po Basin (N Italy, black triangles, 06GL sites; white squares, 10SS sites; black stars, 06SS sites). 
in Italy. We considered 29 representative sites (Lombardia and Emilia-Romagna regions) that were sampled mainly twice (86 sample data; Supplementary Tab. 1). The macroinvertebrate data originate from the fieldwork activities performed from 2009 to 2015. Similar to the Segura Basin, agriculture and flow alterations can be considered the main pressures in the area (Laini et al., 2011; Guareschi et al., 2014). We considered types, reference values and class boundary values according to those published in the Italian ministerial decree DM 260/2010. The data set encompasses three river types from lowland to Apennine streams (Tab. 1, see details on Italian hydro-regions in Buffagni et al., 2008).

According to the Köppen-Geiger climate map of Europe (Peel et al., 2007), the study area in SE Spain is classified mostly as arid (code: BSk), while Italian regions are temperate (code: $\mathrm{Cfa}$ ).

\section{Macroinvertebrate indices: IBMWP, IASPT and STAR_ICMi}

We defined low-abundance taxa as all the taxa whose abundance was $\leq 3$ individuals per sample, which corresponds to the first abundance class in the IBMWP index, and as $\leq 3$ per $0.5 \mathrm{~m}^{2}$ for the quantitative STAR_ICMi. Similar criteria have been considered in other studies (Bradley and Ormerod, 2002; Gillies et al., 2009). The response of three different macroinvertebrate-based indices, IBMWP (Iberian Biological Monitoring Working Party), IASPT (IBMWP value/number of families) and STAR_ICMi (Intercalibration Multimetric Index), to LAT exclusion was tested. The first two indices were tested with the Spanish data set, while the Italian data set was used with the last one (see the details below).

The taxonomic resolution needed to calculate these indices is the family level and five "Ecological status" levels

Tab. 1. Code and description for each river type in the study area. The details for each site are available in Supplementary Tab. 1.

\begin{tabular}{ll} 
Code & Description \\
\hline $\mathrm{T} 1$ & Temporary streams \\
\hline $\mathrm{T} 2$ & Evaporite calcareous at medium altitude \\
\hline $\mathrm{T} 4$ & Calcareous headwaters at medium and high altitude \\
\hline $\mathrm{T} 5$ & Large watercourse \\
& \\
\hline Code & Description \\
\hline 06GL & Floodplain watercourse originated from lakes \\
\hline 06SS & Floodplain streams \\
\hline 10SS & Northern Apennine streams
\end{tabular}

have been established according to European legislation (WFD 2000/60/CE, European Commission 2000) for IBMWP and STAR_ICMi. IBMWP is the most widely used index in Spanish Mediterranean rivers (Alba-Tercedor et al., 2002; Munné and Prat, 2009). It is currently the official index proposed in Spanish rivers (MAGRAMA, 2015) and is an adaptation of the British BMWP scoring system for the Iberian Peninsula, where each family presents a score from 0 to 10 according to their known tolerance to pollution. The IBMWP index is a single metric index (Munné and Prat, 2009) and the sample value is obtained by summing these family scores. This index is considered a simple one (Couto-Mendoza et al., 2015) with a multihabitat semi-quantitative kick procedure in the field (Jáimez-Cuéllar et al., 2002). IASPT represents a sensitive taxa index that is easily calculated for each sample as the IBMWP value divided by the number of scoring families detected. It was calculated only for the Spanish data set as this index is currently recognised as a biomonitoring tool in Spain and is commonly used in this area (e.g., SánchezMontoya et al., 2010). Unlike the other indices, STAR_ICMi is a multimetric index and is the official index used in Italy for assessing water course quality statuses according to European legislation (Buffagni et al., 2006, 2008). It requires a quantitative sampling activity referee on a surface $\left(0.5 \mathrm{~m}^{2}\right.$ or $1.0 \mathrm{~m}^{2}$ depending on the Italian hydro-regions) and has also been used in Europe as an Intercalibration Common Metric Index (Buffagni et al., 2006). It is composed of six metrics: ASPT (Average Score Per Taxon), logarithm of the abundances of the selected families of Ephemeroptera, Plecoptera, Trichoptera and Diptera abundances $(\log ($ sel_EPTD +1$))$, total number of taxa, number of EPT taxa, 1 minus the relative abundance of Gastropoda, Oligochaeta and Diptera (1-GOLD) and the Shannon index. After calculating the metrics, they were normalised with the reference community values and weighed (see Buffagni et al., 2006, 2007; and the Italian ministerial decree DM 260/2010 for further details).

\section{Statistical analyses}

First of all, the percentage of LAT and the contribution of each taxonomic group (mainly Order) to the total number of LAT were calculated. To refine the analysis and to deal with the first goal, the Indicator Value analysis (IndVal) was carried out to select specific rare families per river type (Dufrêne and Legendre, 1997; De Cáceres et al., 2010). Such affinity was calculated according to the frequency of each taxon in the previously identified groups by taking into account only the sub-communities that composed of LAT. The significance of the Indicator Value (IV) was tested by a Monte Carlo test (999 runs), and the alpha level was set at 0.05 .

In order to test the effect of excluding LAT on river biomonitoring indices, they were removed from each 
sample after considering $100 \%$ and $50 \%$ of LAT (see details below). Then each index was recalculated and all the samples were reclassified in the corresponding ecological classes. The first case corresponded to excluding the entire pool of LAT (e.g., relevant problems in the sorting or picking phase, operators have little experience). We also tested a more conservative exclusion threshold, which corresponded to a $50 \%$ loss of LAT. To do this, the excluded LAT were obtained by considering 100 randomisations of LAT constant loss one by one, and by stopping at the value that equalled a $50 \%$ loss of the total LAT pool. At this point, we once again recalculated each index and all the samples were reclassified in the corresponding ecological classes.

The differences between the index values obtained before and after totally excluding LAT were statistically tested by a non-parametric Mann-Whitney test. The results were reported for both the Spanish and the Italian data sets, and even after splitting each data set according to its ecological classes and river type. The behaviour of each index was also studied graphically by focusing on the trend obtained after performing the LAT loss simulations.

To determine whether possible changes in ecological status were equally distributed among the ecological quality classes, we classified the sample data into three classes: High, Good and Less than Good (codes: H, G, <
G). The boundary between Good and Moderate is crucial according to European legislation (WFD 2000/60/CE) because it sets the targets for restoration plans in measuring programmes of water bodies which fail the environmental objectives of achieving a good ecological status. All the statistical analyses were performed with the statistical computing R software (R Development Core Team, 2013) with packages "Vegan", "ade4" and "indicspecies".

\section{RESULTS}

\section{Low-abundance taxa characterisation}

Ninety-five macroinvertebrate taxa (92 families, plus Hydrachnidia, Ostracoda, Oligochaeta) were found in the Spanish basin (mean $\pm \mathrm{SD}=30 \pm 11$; SD, standard deviation), with a mean value of 11 taxa $( \pm 5)$ as LAT (details in Tab. 2). Ninety-one of the 95 taxa were identified as rare at least once. The taxa with low abundances belonged mainly to Diptera (20\%), Trichoptera and Coleoptera (both 14\%) in this area (Fig. 2).

The IndVal analysis stressed just one indicator family in river types $\mathrm{T} 1$ and $\mathrm{T} 2$ as Baetidae and Tabanidae, respectively. Larger groups of indicator families were obtained for types T4 and T5. Cordulegasteridae and Gyrinidae showed the highest IV for T4, with Hydroptil-

Tab. 2. Mean number $( \pm \mathrm{SD})$ of the low-abundance taxa (LAT) for each river type in each data set. The total number of taxa (TT) and the total number of LAT are also displayed.

\begin{tabular}{lccccccccc} 
& T1 & T2 & T4 & T5 & Total & 06GL & 10SS & 06SS & Total \\
LAT & $8 \pm 5$ & $10 \pm 3$ & $15 \pm 3$ & $10 \pm 5$ & 91 & $8 \pm 3$ & $10 \pm 4$ & $8 \pm 3$ & 90 \\
\hline TT & 73 & 73 & 83 & 55 & 95 & 68 & 66 & 42 & 92 \\
\hline
\end{tabular}

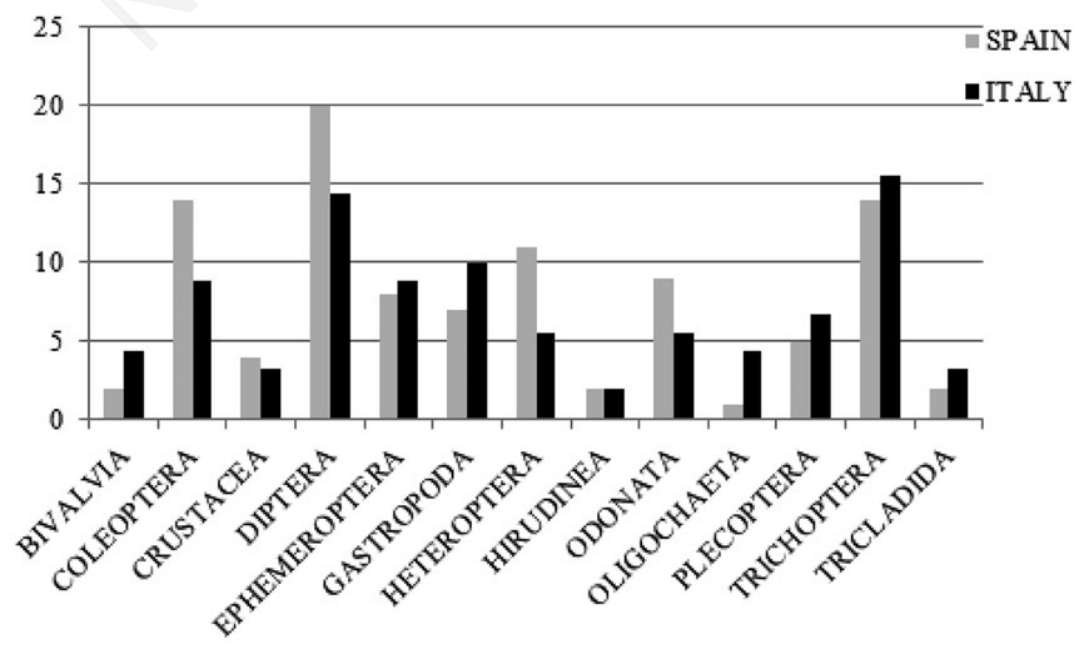

Fig. 2. Distribution of LAT (in \%) among the main taxonomic groups (mainly Order). Spanish results are labelled in grey and Italian ones in the darker tone. 
idae, Ceratopogonidae and Philopotamidae in the T5 ecosystems (Tab. 3).

Regarding the Italian dataset, 92 taxa (91 families, plus Hydrachnidia) were detected ( $21 \pm 5$ per sample) with a mean value of $9 \pm 3$ LAT per sample. Ninety taxa were identified as rare at least once (Tab. 2), where the highest percentage of low-abundance taxa belonged to Tri- choptera (16\%), followed by Diptera, Gastropoda and Coleoptera (Fig. 2).

The IndVal analysis showed only two families as being characteristic LAT in the 06GL river type (Corbiculidae and Aphelocheiridae), whereas a larger number of taxa were found in the other types (Tab. 4). Dryopidae, Leuctridae and Oligoneuriidae showed the highest IV for

Tab. 3. The IndVal results for the Spanish data set of LAT (Segura Basin) at the family level.

\begin{tabular}{|c|c|c|c|c|}
\hline Order & Family & $\mathrm{T}$ & IV & P value \\
\hline Ephemeroptera & Baetidae & $\mathrm{T} 1$ & 0.19 & $0.050 *$ \\
\hline Diptera & Tabanidae & $\mathrm{T} 2$ & 0.37 & $0.005 * *$ \\
\hline Odonata & Cordulegasteridae & $\mathrm{T} 4$ & 0.32 & $0.005 * *$ \\
\hline Coleoptera & Gyrinidae & $\mathrm{T} 4$ & 0.31 & $0.020 *$ \\
\hline Megaloptera & Sialidae & $\mathrm{T} 4$ & 0.29 & $0.020 *$ \\
\hline Diptera & Psychodidae & $\mathrm{T} 4$ & 0.26 & $0.025^{*}$ \\
\hline Trichoptera & Polycentropodidae & $\mathrm{T} 4$ & 0.25 & $0.040^{*}$ \\
\hline Odonata & Aeshnidae & $\mathrm{T} 4$ & 0.24 & $0.035^{*}$ \\
\hline Ephemeroptera & Leptophlebiidae & $\mathrm{T} 4$ & 0.24 & $0.010 * *$ \\
\hline Plecoptera & Perlodidae & $\mathrm{T} 4$ & 0.21 & $0.040 *$ \\
\hline Trichoptera & Hydroptilidae & $\mathrm{T} 5$ & 0.42 & $0.005 * *$ \\
\hline Diptera & Ceratopogonidae & $\mathrm{T} 5$ & 0.34 & $0.020 *$ \\
\hline Trichoptera & Philopotamidae & $\mathrm{T} 5$ & 0.32 & $0.020 *$ \\
\hline Odonata & Calopterygidae & $\mathrm{T} 5$ & 0.31 & $0.005 * *$ \\
\hline Gastropoda & Planorbidae & $\mathrm{T} 5$ & 0.31 & $0.005 * *$ \\
\hline Coleoptera & Dytiscidae & $\mathrm{T} 5$ & 0.29 & $0.010 * *$ \\
\hline Gastropoda & Ancylidae & $\mathrm{T} 5$ & 0.22 & $0.050 *$ \\
\hline
\end{tabular}

$T$, river type; $I V$, indicator value; $* * P<0.01 ; * P<0.05$.

Tab. 4. The IndVal results for the Italian basin of LAT (Po Basin) at the family level.

\begin{tabular}{llccc} 
Order & Family & T & IV & 0.26 \\
Bivalvia & Corbiculidae & $06 \mathrm{GL}$ & $0.035^{*}$ & $0.050^{*}$ \\
\hline Hemiptera & Aphelocheiridae & $6 \mathrm{SS}$ & 0.58 & 0.005 \\
\hline Coleoptera & Dryopidae & $6 \mathrm{SS}$ & 0.30 & $0.020^{*}$ \\
\hline Plecoptera & Leuctridae & $6 \mathrm{SS}$ & 0.29 & $0.005^{* *}$ \\
\hline Ephemeroptera & Oligoneuriidae & $6 \mathrm{SS}$ & 0.27 & $0.040^{*}$ \\
\hline Ephemeroptera & Ephemerellidae & $6 \mathrm{SS}$ & 0.25 & $0.040^{*}$ \\
\hline Trichoptera & Polycentropodidae & $6 \mathrm{SS}$ & 0.20 & $0.050^{*}$ \\
\hline Amphipoda & Gammaridae & $10 \mathrm{SS}$ & 0.40 & $0.005^{* *}$ \\
\hline Diptera & Athericidae & $10 \mathrm{SS}$ & 0.31 & $0.035^{*}$ \\
\hline Diptera & Empididae & $10 \mathrm{SS}$ & 0.27 & $0.005^{* *}$ \\
\hline Coleoptera & Dytiscidae & $10 \mathrm{SS}$ & 0.23 & $0.040^{*}$ \\
\hline Plecoptera & Perlidae & $10 \mathrm{SS}$ & 0.23 & $0.010^{* *}$ \\
\hline Trichoptera & Limnephilidae & $10 \mathrm{SS}$ & 0.17 & $0.040^{*}$ \\
\hline Trichoptera & Sericostomatidae & $10 \mathrm{SS}$ & 0.13 & $0.025^{*}$ \\
\hline Coleoptera & Scirtidae & $10 \mathrm{SS}$ & 0.13 & $0.045^{*}$ \\
\hline Hemiptera & Gerridae & $10 \mathrm{SS}$ & 0.11 & $0.040^{*}$
\end{tabular}

$T$, river type; $I V$, indicator value; $* * P<0.01 ; * P<0.05$. 
floodplain rivers (06SS), while Athericidae and Empididae were identified in Apennine streams (10SS, Tab. 4).

\section{Effect of excluding low-abundance taxa on single metric indices: IBWMP and IASPT}

Excluding the entire pool of LAT $(100 \%)$ resulted in significant differences compared with the IBMWP results $(\mathrm{W}=3321 ; \mathrm{P}<0.0001)$. The original IBMWP mean value was 148; on the contrary when the index was recalculated, we obtained a mean value that equalled 93 . The ecological quality classification of 29 of the 30 sampling sites changed at least once, and the ecological status of $78 \%$ of the samples changed to a minor class (see Tab. 5). Moreover, $82 \%$ of the values first classified as High shifted to a minor status (Good). Similar results were obtained (74$75 \%$ ) when the starting point was Good or Less than Good. Substantial changes were noted for each river type in the analysis (from $33 \%$ to $100 \%$ ), which was especially true for the T2 streams that exhibited huge changes in quality assessment when the starting points were High or Less than Good classes.

The $50 \%$ randomised LAT loss also led to relevant changes in the IBMWP values, but the percentage of class changes lowered compared to the total LAT loss (Tab. 5). The ecological status of about half the overall samples (48\%) changed ( 24 of the 30 sites changed at least once). Once again, percentages were similar among different classes (43-53\%). When focusing on each river type separately, the patterns were basically the same (compared with the total LAT loss), with changes falling between $33 \%$ and $100 \%$ of cases depending on ecological class. When LAT were not considered, all the river types presented similar patterns, and their IBMWP values clearly and constantly dropped (Fig. 3).

Unlike the IBMWP results, the IASPT recalculations (when all the LAT were excluded) gave values that did not statistically differ from the original ones $(\mathrm{W}=1382$, $\mathrm{P}=0.1906$ ). Graphically, the IASPT behaviour of LAT loss appeared constant and displayed a horizontal trend, with the only exception being river type $\mathrm{T} 1$, where more diversified responses were obtained (Fig. 4).

\section{Effect of excluding low-abundance taxa on a multimetric index: STAR_ICMi}

The exclusion of all the LAT (100\%) led to significant differences when we compared the STAR_ICMi results $(\mathrm{W}=3781 ; \mathrm{P}<0.0001)$. The original STAR_ICMi mean value was 0.74 , which became 0.62 when recalculated. The ecological quality classification of 19 of the 29 sampling sites underwent at least one class change. The ecological status of $41 \%$ of all the samples changed to a minor class. Similar values and patterns were obtained through different ecological classes (36-41\%), except when the starting point was High class (100\% change, but a limited number of data were available; Tab. 6).

The $50 \%$ randomised loss of LAT brought about changes in the STAR_ICMi values (Tab. 6). The ecological status of $33 \%$ of the overall samples changed (17 of 29 sites underwent at least one change). Once again, the percentages were similar among the different classes (23$36 \%$ ), expect when the original starting point was the High class. When focusing on each river type separately, and compared to the total LAT loss, the percentage of class changes lowered, except for river type 06SS (Tab. 6). When we graphically analysed the behaviour of STAR_ICMi, the response patterns were not as clear as they were for the other indices. A decreasing tendency seemed the commonest behaviour in the three studied river types when LAT were excluded (Fig. 5).

\section{DISCUSSION}

\section{Low-abundance taxa}

Despite the climatic and environmental differences in the two study areas, LAT belonged mainly to the same or-

Tab. 5. Number of changes of ecological quality classes for the $100 \%$ or $50 \%$ LAT loss. The results are displayed after considering the overall number of samples (Total), divided by river type (T1, T2, T4, T5) and ecological class (the classification represents the starting point class before excluding LAT) in the Spanish data set. Number of sampling data per river type is also displayed.

\begin{tabular}{|c|c|c|c|c|c|c|c|c|c|c|}
\hline \multicolumn{11}{|c|}{ Spain (Segura Basin) } \\
\hline & Total & Total & \multicolumn{2}{|c|}{$\mathrm{T} 1(\mathrm{n}=16)$} & \multicolumn{2}{|c|}{ T2 $(\mathrm{n}=\mathbf{2 5})$} & \multicolumn{2}{|c|}{$\mathrm{T} 4(\mathrm{n}=34)$} & \multicolumn{2}{|c|}{ T5 $(n=6)$} \\
\hline & $100 \%$ & $50 \%$ & $100 \%$ & $50 \%$ & $100 \%$ & $50 \%$ & $100 \%$ & $50 \%$ & $100 \%$ & $50 \%$ \\
\hline Changes & $78 \%$ & $48 \%$ & $12(75 \%)$ & $9(56 \%)$ & $21(84 \%)$ & $13(52 \%)$ & $27(79 \%)$ & $16(47 \%)$ & $3(50 \%)$ & $1(17 \%)$ \\
\hline No changes & $22 \%$ & $52 \%$ & $4(25 \%)$ & $7(44 \%)$ & $4(16 \%)$ & $12(48 \%)$ & $7(21 \%)$ & $18(53 \%)$ & $3(50 \%)$ & $5(83 \%)$ \\
\hline Classes & & & & & & & & & & \\
\hline Good & $74 \%$ & $43 \%$ & $7(88 \%)$ & $5(63 \%)$ & $13(76 \%)$ & $6(35 \%)$ & $5(71 \%)$ & $4(57 \%)$ & $1(33 \%)$ & 0 \\
\hline$<$ Good & $75 \%$ & $50 \%$ & $3(60 \%)$ & $2(40 \%)$ & $3(100 \%)$ & $2(67 \%)$ & - & - & - & - \\
\hline
\end{tabular}


ders in both data sets (e.g., Diptera, Trichoptera and Coleoptera) and were basically those stressed by Nijboer and Schmidt-Kloiber (2004) for Dutch streams. When focusing on the Spanish data set, and according to the crite- rion of IV $>25$ as a key value to judge an indicator taxon as being adequate (Bonada et al., 2008, following Dufrêne and Legendre, 1997), Baetidae was not a good indicator for the T1 streams. On the contrary in the T2 streams, Ta-

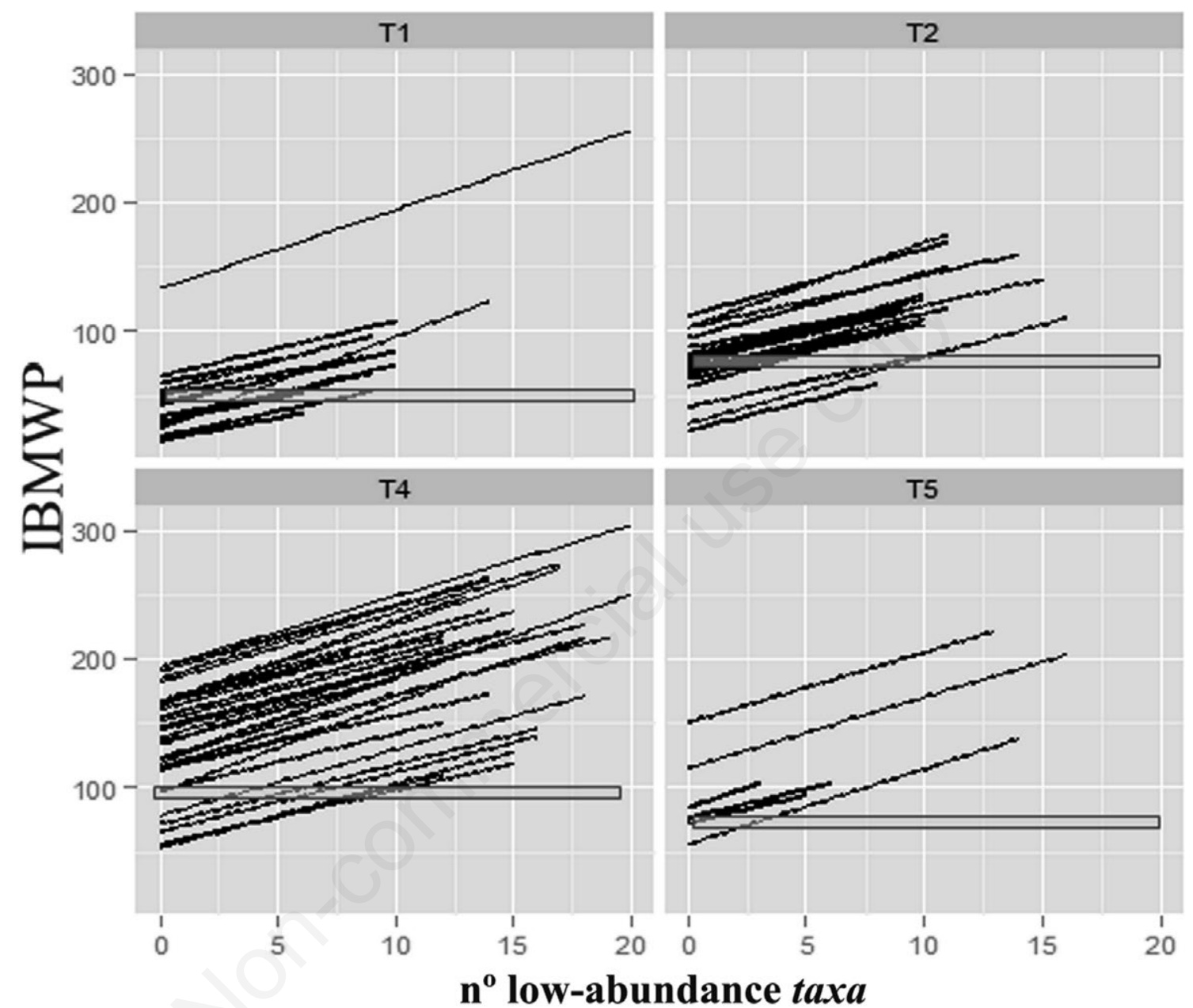

Fig. 3. IBMWP index behaviour per river type (T1, T2, T4, T5) after randomisations of constant LAT loss. The boundary value between the Good and Moderate conditions is displayed. The index values are displayed on the y-axis and the number of considered LAT is found on the $\mathrm{x}$-axis.

Tab. 6. Number of changes of ecological quality classes for the $100 \%$ or $50 \%$ LAT loss. The results are displayed after considering the overall number of samples (Total), divided by river type (06GL, 10SS, 06SS) and ecological class (the classification represents the starting point class before excluding LAT) in the Italian data set. Number of sampling data per river type is also displayed.

\begin{tabular}{|c|c|c|c|c|c|c|c|c|}
\hline \multicolumn{9}{|c|}{ Italy (Po Basin) } \\
\hline & \multirow{2}{*}{$\begin{array}{l}\text { Total } \\
100 \%\end{array}$} & \multirow{2}{*}{$\begin{array}{l}\text { Total } \\
\mathbf{5 0} \%\end{array}$} & \multicolumn{2}{|c|}{$06 \mathrm{GL}(\mathrm{n}=55)$} & \multicolumn{2}{|c|}{$10 S S(n=24)$} & \multicolumn{2}{|c|}{ 06SS $(n=7)$} \\
\hline & & & $100 \%$ & $50 \%$ & $100 \%$ & $50 \%$ & $100 \%$ & $50 \%$ \\
\hline Changes & $41 \%$ & $33 \%$ & $21(38 \%)$ & $17(31 \%)$ & $10(42 \%)$ & $7(29 \%)$ & $4(57 \%)$ & $4(57 \%)$ \\
\hline No changes & $59 \%$ & $67 \%$ & $34(62 \%)$ & $38(69 \%)$ & $14(58 \%)$ & $17(71 \%)$ & $3(43 \%)$ & $3(43 \%)$ \\
\hline \multicolumn{9}{|l|}{ Classes } \\
\hline High & $100 \%$ & $100 \%$ & - & - & - & - & $3(100 \%)$ & $3(100 \%)$ \\
\hline Good & $41 \%$ & $36 \%$ & $9(38 \%)$ & $8(33 \%)$ & $8(50 \%)$ & $7(44 \%)$ & $1(25 \%)$ & $1(25 \%)$ \\
\hline$<$ Good & $36 \%$ & $23 \%$ & $12(39 \%)$ & $9(29 \%)$ & $2(25 \%)$ & $0(0 \%)$ & - & - \\
\hline
\end{tabular}


banidae needed special attention during sample and sorting activities, as did a large group of taxa dominated by Cordulegasteridae and Hydroptilidae for the T4 and T5 streams, respectively. Cordulegasteridae larvae (genus Cordulegaster), Tabanidae and Athericidae (see below) are generally predators of other aquatic invertebrates (Tachet et al., 2010). Members of these feeding groups have already been stressed as being relatively less abundant than prey species (Spencer, 2000). Hydroptilidae larvae (Trichoptera) usually prefer specific microhabitats with submerged vegetation where they anchor their cocoons which, coupled with their limited size and lack of movements (under dry and wet conditions) (Tachet et al., 2010), may make them particularly difficult to detect.

None of the taxa stressed by the analysis was characterised by extreme IBMWP scores, and higher values were depicted by some Odonata (e.g., Cordulegasteridae) or Trichoptera (e.g., Philopotamidae). Most of the indicator taxa presented intermediate values, basically with scores of around 3, 4, or even 6 points, as confirmed by the IASPT response to LAT loss (Fig. 4). The mean taxa scores did not change, but stabilised with values between 4 and 6 . In this situation, LAT presented a comparable IBMWP score with the commonest taxa. These results (Fig. 4) agree with the research of Nijboer and Schmidt-Kloiber (2004), who found that the mean scores for saprobic valences were similar for both taxa types (low and high abundances). If LAT had been taxa with an extreme IBMWP score (1 or 10), the IASPT responses to their loss would have shifted towards a marked change in their slopes.

According to the Italian results, it was difficult to suggest specific LAT for the 06GL rivers if we considered that the IndVal stressed taxa with IV came close to 25. On the contrary, Dryopidae (Coleoptera) and Athericidae (Diptera) were underlined as characteristic LAT in 06SS and 10SS, respectively. Special attention needs to be paid

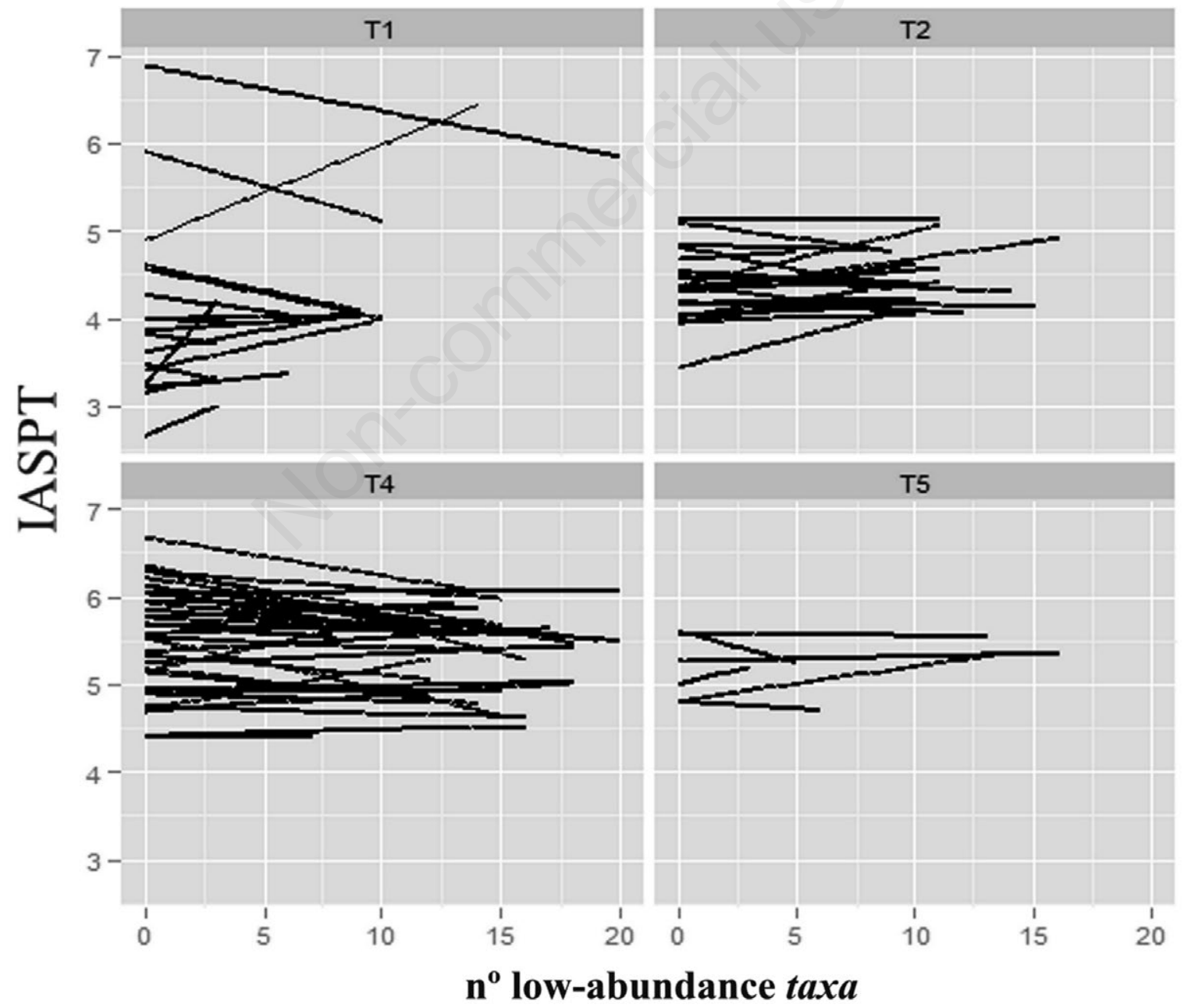

Fig. 4. IASPT index behaviour per river type (T1, T2, T4, T5) after randomisations of constant LAT loss. The index values are displayed on the $\mathrm{y}$-axis and the number of considered LAT is found on the $\mathrm{x}$-axis. 
to these taxa in all the sampling phases and for all laboratory activities. Dryopidae larvae are generally semiaquatic or riparian (Jäch and Balke, 2008) and are, therefore, rarer to detect during sampling activity as only adults are strictly aquatic. Furthermore, Dryopidae have already been stressed as infrequent in low mountainous streams in other European countries (Slovakia: Zatovičová et al., 2004). Regarding specific LAT features, other studies have generally found that these taxa are associated with standing or slowly flowing waters (Nijboer and Schmidt-Kloiber, 2004).

Our results in both data sets only partially confirmed this finding by considering that a heterogeneous group of LAT was found. This group was composed of some lotic preference taxa, but also some highly diverse taxa (Coleoptera, Diptera), and even some strictly lentic ones (Odonata, Gastropoda, and Hemiptera). However, benthic sampling methodologies like those utilised (D-net and Surber, following official legislation) could also be the reason for the low abundance found in some groups (e.g., swimmers or surface skaters). Most of these taxa (e.g., Coleoptera or Hemiptera) live on the water surface or among vegetation, and can easily escape sampling nets. Nevertheless, the LAT identified herein cannot be considered rare or endemic in terms of small range areas, especially given taxonomic resolution (family level).

\section{Performance of indices and implication for bioassessment}

Excluding LAT resulted in underestimating ecological status (values lower than reality) for STAR_ICM and IBMWP indices. This effect became considerably stronger after applying the IBMWP index, with relevant
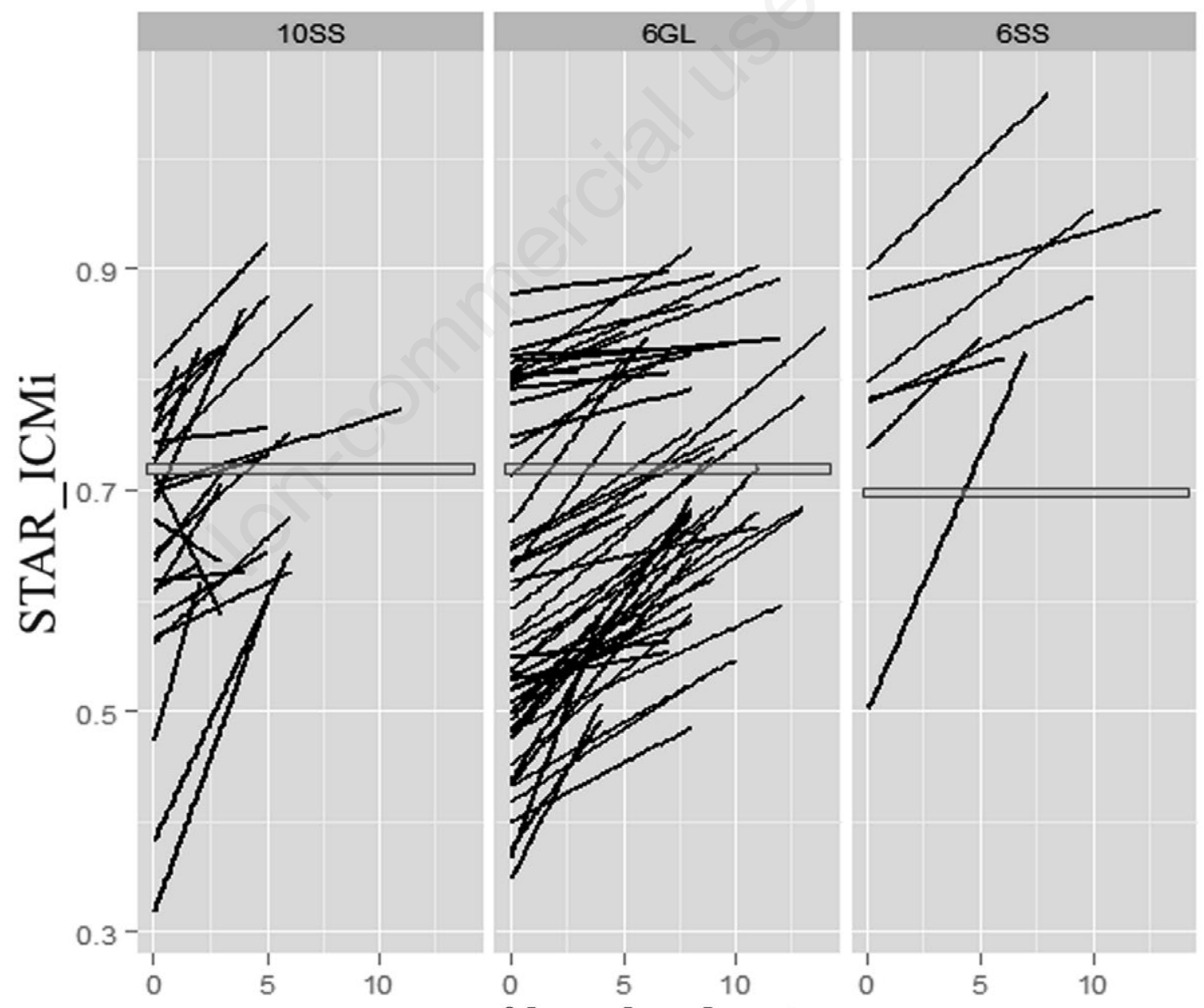

$n^{0}$ low-abundace taxa

Fig. 5. STAR_ICM index behaviour per river type (10SS, 06GL, 06SS) after randomisations of constant LAT loss. The boundary value between the Good and Moderate conditions is displayed. The index values are displayed on the y-axis and the number of considered LAT is found on the $\mathrm{x}$-axis. 
changes in the ecological evaluations. This is strictly related with the index formula, which exclusively represents a sum of family scores and is strongly affected by a reduction in the total recognised taxa.

Different outcomes were detected when focusing on the IASPT index. This index did not appear sensitive when LAT were excluded from three of the four Mediterranean river types, and displayed a contrasting response in temporary rivers (T1). Applying biomonitoring procedures to temporary aquatic ecosystems is currently one on the main bioassessment challenges and requires specific tools (Nikolaidis et al., 2013; Datry et al., 2014; Prat et al., 2014). The general observed lack of sensitivity of this index can be considered an interesting attribute (i.e., no specific knowledge or experience required), but this approach may be questionable, or even dangerous (Metzeling et al., 2003; Haase et al., 2006). We should also consider that the IASPT index has been reported to be less sensitive to stressors than the IBMWP index in Mediterranean rivers (Sánchez-Montoya et al., 2010).

The Italian index STAR_ICM gave an intermediate response compared to the other indices. Following LAT loss, the results were generally underestimated, but more slightly than for the IBMWP index. Once again, this is probably related with the index formula. As it was a multimetric index, and not just a mathematic sum, it could be less affected by the reduction in the total taxa considered herein. Richness metrics formed part of the index (e.g., total of families, total EPT taxa), but the metrics with the heaviest weight in the definition of the index was the Average Score Per Taxon (ASPT) value. Knowing the specific behaviour of the Spanish ASPT (investigated herein) could help explain the attenuated STAR tendencies.

Unlike our results, Nijboer and Schmidt-Kloiber (2004) reported that excluding LAT overestimated the ecological quality class in Dutch lowland streams with the AQEM software (Hering et al., 2004). These contrasting findings, which are especially strong between IBMWP and AQEM, may be due to the different geographic contexts and river types considered (e.g., Northern $v s$ Southern Europe), but could also be due to specific differences between protocols (e.g., taxonomic resolution, sampling area). Despite the AQEM method and STAR_ICMi presenting similar procedures (Hering et al., 2006), contrasting results were obtained as LAT exclusion did not generally lead to overestimates in the Italian data set. Nevertheless, in both cases (underestimation and overestimation), these mismatches could have serious consequences for environmental agencies and water managers during environmental management (e.g., restoration where it is not necessary), which can provide equivocal pictures of river ecosystem health.

\section{CONCLUSIONS}

Our study is one of the first attempts to test the effects of excluding LAT in several widely used European indices. Previous studies have tested macroinvertebrates at the genus or species level (Cao et al., 1998; Resh et al., 2005), and have mainly examined the effects of LAT on richness metrics. Our results demonstrated that even at the family level and in two different study areas, LAT represent a large part of overall richness. Their exclusion strongly lowered the number of taxa in the samples regardless river typology, with effects on bioassessment depending on the index employed. In this context, the implementation of quality control mechanisms into macroinvertebrate assessment procedures seems recommendable.

Finally, by considering the increasing impacts and challenges of alien species on aquatic ecosystems (Havel et al., 2015; Fenoglio et al., 2016), alien taxa must be specially considered because they can be generally characterised by initial low abundances in their first invasion phases. Indeed, in our study, Corbiculidae (e.g., Corbicula fluvialis) are reported as LAT in some Italian rivers. This fact may lead to some mismatches or variations in the final index scores, and similar problems have already been stressed in other European countries (Gabriel et al., 2005). Specific reflexions and future adjustments to studied systems in both countries should be made (e.g., definition of specific tolerance classes or periodically reviewing the taxa list by considering possible taxonomic modifications and future invaders) to improve ecological assessment tools in freshwater ecosystems.

\section{ACKNOWLEDGMENTS}

The authors would like to thank Rossano Bolpagni and Stefano Fenoglio for organising this special issue of the Journal of Limnology. M.M. Sánchez-Montoya was supported by a Marie-Curie postdoctoral fellowship (MCIEF; FP7-people-2012-IEF; CLITEMP Project: 330466). The authors also thank Antonio Guareschi for his insightful comments on an earlier version of this manuscript and Helen Warburton for revising the English language.

\section{REFERENCES}

Alba-Tercedor J, Jáimez-Cuellar P, Álvarez M, Avilés J, Bonada N, Casas J, Mellado A, Ortega M, Pardo I, Prat N, Rieradevall M, Robles S, Sáinz-Cantero CE, Sánchez-Ortega A, Suárez ML, Toro M, Vidal-Abarca MR, Vivas S, Zamora-Muñoz C, 2002. [Caracterización del estado ecológico de ríos mediterráneos ibéricos mediante el índice IBMWP (antes

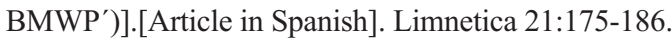

Armitage PD, Moss D, Wright JF, Furse MT, 1983. The per- 
formance of a new biological water quality score system based on macroinvertebrates over a wide range of unpolluted running-water sites. Water Res. 7:333-347.

Barbour MT, Gerritsen J, Snyder BD, Stribling JB, 1999. Rapid Bioassessment Protocols for Use in Streams and Wadeable Rivers: Periphyton, Benthic Macroinvertebrates and Fish, Second Edition. EPA 841-B-99-002. U.S. Environmental Protection Agency; Washington, D.C.

Birk S, Bonne W, Borja A, Brucet S, Courrat A, Poikane S, Solimini A, van de Bund W, Zampoukas N, Hering D, 2012. Three hundred ways to assess Europe's surface waters: an almost complete overview of biological methods to implement the Water Framework Directive. Ecol. Ind. 18:31-41.

Bo T, Doretto A, Laini A, Fenoglio S, 2017. Biomonitoring with macroinvertebrate communities in Italy: What happened to our past and what's the future? J. Limnol. 76(Suppl.1):2128. [Epub 17 Oct 2016].

Bonada N, Prat N, Resh VH, Statzner B, 2006. Developments in aquatic insect biomonitoring: a comparative analysis of recent approaches. Annu. Rev. Entomol. 51:495-523.

Bonada N, Rieradevall M, Dallas H, Davis J, Day J, Figueroa R, Resh VN, Prat N, 2008. Multi-scale assessment of macroinvertebrate richness and composition in Mediterranean-climate rivers. Freshwater Biol. 53:772-788.

Bradley DC, Ormerod SJ, 2002. Evaluating the precision of kick-sampling in upland streams for assessments of longterm change: the effects of sampling effort, habitat and rarity. Arch. Hydrobiol. 155:199-221.

Bruno D, Belmar O, Sánchez-Fernández D, Guareschi S, Millán A, Velasco J, 2014. Responses of Mediterranean aquatic and riparian communities to human pressures at different spatial scales. Ecol. Ind. 45:456-464.

Buffagni A, Erba S, Cazzola M, Murray-Bligh J, Soszka H, Genoni P, 2006. The Star common metrics approach to the WFD intercalibration process: full application for small, lowland rivers in three European countries. Hydrobiologia 566:379-399.

Buffagni A, Erba S, Furse MT, 2007. A simple procedure to harmonize class boundaries of assessment systems at the panEuropean scale. Environ. Sci. Policy 10:709-724.

Buffagni A, Erba S, Pagnotta R, 2008. [Definizione dello stato ecologico dei fiumi sulla base dei macroinvertebrati bentonici per la 2000/60/EC (WFD): il sistema di classificazione MacrOper].[Report in Italian]. Accessed on: 17 February 2015. Available from: http://www.irsa.cnr.it/Docs/Notiz/ notiz2008_\%28NS\%29.pdf

Buss DF, Carlisle DM, Chon TS, Culp J, Harding JS, KeizerVlek HE, Robinson WA, Strachan S, Thirion C, Hughes RM, 2015. Stream biomonitoring using macroinvertebrates around the globe: a comparison of large-scale programs. Environ. Monit. Assess. 187:1-21.

Cao Y, Williams D, Williams NE, 1998. How important are rare species in aquatic community ecology and bioassessment? Limnol. Oceanogr. 43:1403-1409.

Cao Y, Williams D, 1999. Rare species are important in bioassessment (Reply to the comment by Marchant). Limnol. Oceanogr. 44:1841-1842.

Cao Y, Larsen DP, Thorne RS, 2001. Rare species in multivariate analysis for bioassessment: some consideration. J. N. Am. Benthol. Soc. 20:144-153.
Clarke RT, Murphy JF, 2006. Effects of locally rare taxa on the precision and sensitivity of RIVPACS bioassessment of freshwaters. Freshwater Biol. 51:1924-1940.

Couto-Mendoza MT, Vieira-Lanero R, Cobo F, 2015. More complexity does not always mean more accuracy: the case of IBMWP and METI in NW Spain. Ecohydrology 8:595609.

Datry T, Larned ST, Tockner K, 2014. Intermittent rivers: a challenge for freshwater ecology. BioScience 64:229-235.

De Cáceres M, Legendre P, Moretti M, 2010. Improving indicator species analysis by combining groups of sites. Oikos 119:1674-1684.

Dolédec S, Statzner B, 2010. Responses of freshwater biota to human disturbances: contribution of J-NABS to developments in ecological integrity assessments. J. N. Am. Benthol. Soc. 29:286-311.

Dufrêne M, Legendre P, 1997. Species assemblages and indicator species: the need for a flexible asymmetrical approach. Ecol. Monogr. 67:345-366.

European Commission, 2000. Directive 2000/60/EC of the European Parliament of the Council of 23rd October 2000 establishing a framework for community action in the field of water policy. OJ L 327, 22.12.2000, p. 1-73.

Fenoglio S, Bonada N, Guareschi S, López-Rodríguez M., Millán A, Tierno de Figueroa JM, 2016. Freshwater ecosystems and aquatic insects: A paradox in biological invasions. Biol. Lett. 12:20151075.

Gabriels W, Goethals PLM, De Pauw N, 2005. Implications of taxonomic modifications and alien species on biological water quality assessment as exemplified by the Belgian Biotic Index method. Hydrobiologia 542:137-150.

Gaston KJ, 1994. Rarity. Population and community biology. Series 13. Chapman \& Hall, London: 395 pp.

Gillies CL, Hose GC, Turak E, 2009. What do qualitative rapid assessment collections of macroinvertebrates represent? A comparison with extensive quantitative sampling. Environ. Monit. Assess. 149:99-112.

Gray BR, 2005. Selecting a distributional assumption for modelling relative densities of benthic macroinvertebrates. Ecol. Model. 185:1-12.

Guareschi S, Laini A, Racchetti E, Bo T, Fenoglio S, Bartoli M, 2014. How do hydromorphological constraints and regulated flows govern macroinvertebrate communities along an entire lowland river? Ecohydrology 7:366-377.

Jáimez-Cuéllar P, Vivas S, Bonada N, Robles S, Mellado A, Álvarez M, Avilés J, Casas J, Ortega M, Pardo I, Prat N, Rieradevall M, Sáinz-Cantero CE, Sánchez-Ortega A, Suárez ML, Toro M, Vidal-Abarca MR, Zamora-Muñoz C, AlbaTercedor J, 2002. [Protocolo Guadalmed (PRECE)].[Article in Spanish]. Limnetica 21:187-204.

Haase P, Pauls SU, Schindehütte K, Sundermann A, 2010. First audit of macroinvertebrate samples from an EU Water Framework Directive monitoring program: human error greatly lowers precision of assessment results. J. N. Am. Benthol. Soc. 29:1279-1291.

Haase P, Murray-Bligh J., Lohse S, Pauls S, Sundermann A, Gunn R, Clarke RT, 2006. Assessing the impact of errors in sorting and identifying macroinvertebrate samples. Hydrobiologia 566:505-521.

Havel JE, Kovalenko KE, Thomaz SM, Amalfitano S, Kats LB, 
2015. Aquatic invasive species: challenges for the future. Hydrobiologia 750:147-170.

Hering D, Moog O, Sandin L, Verdonschot PFM, 2004. Overview and application of the AQEM assessment system. Hydrobiologia 516:1-20.

Hering D, Feld CK, Moog O, Ofenböck T, 2006. Cook book for the development of a multimetric index for biological condition of aquatic ecosystems: experiences from the European AQEM and STAR projects and related initiatives. Hydrobiologia 566:311-324.

Jäch MA, Balke M, 2008. Global diversity of water beetles (Coleoptera) in freshwater. Hydrobiologia 595:419-442.

Kroll SA, Ringler NH, De las Heras J, Goméz-Alday JJ, Moratalla A, Briggs RD, 2013. Analysis of anthropogenic pressures in the Segura Watershed (SE Spain), with a focus on inter-basin transfer. Ecohydrology 6:878-888.

Laini A, Bartoli M, Castaldi S, Viaroli P, Capri E, Trevisan M, 2011. Greenhouse gases $\left(\mathrm{CO}_{2}, \mathrm{CH}_{4}\right.$ and $\left.\mathrm{N}_{2} \mathrm{O}\right)$ in lowland springs within an agricultural impacted watershed (Po River plain, northern Italy). Chem. Ecol. 27:177-187.

Laini A, Vorti A, Bolpagni R, Viaroli P, 2014. Small-scale variability of benthic macroinvertebrates distribution and its effects on biological monitoring. Ann. Limnol.-Int. J. Lim. 50:211-216.

Marchant R, Yong C, Williams D, 1999. How important are rare species in aquatic community ecology and bioassessment? A comment on the conclusions of Cao et al. Authors' reply. Limnol. Oceanogr. 44:1840-1842.

Marchant R, 2002. Do rare species have any place in multivariate analysis for bioassessment? J. N. Am. Benthol. Soc. 21:311-313.

Metzeling L, Chessman B, Hardwick R, Wong V, 2003. Rapid assessment of rivers using macroinvertebrates: The role of experience, and comparisons with quantitative methods. Hydrobiologia 510:39-52.

MAGRAMA (Ministerio de Agricultura, Alimentación y Medio Ambiente), 2015. [Criterios de seguimiento y evaluación del estado de las aguas superficiales y las normas de calidad ambiental. Boletín Oficial del Estado-BOE, 219: 8058280677].[Report in Spanish]. Ministerio de Medio Ambiente, Madrid, Spain.

Munné A, Prat N, 2009. Use of macroinvertebrate-based multimetric indices for water quality evaluation in Spanish Mediterranean rivers: an intercalibration approach with the IBMWP index. Hydrobiologia 628:203-225.

Nichols SJ, Norris RH, 2006. River condition assessment may depend on the sub-sampling method: field live-sort versus laboratory sub-sampling of invertebrates for bioassessment. Hydrobiologia 572:195-213.

Nijboer RC, Verdonschot PF, 2004. Rare and common macroinvertebrates: definition of distribution classes and their boundaries. Arch. Hydrob. 161:45-64.

Nijboer RC, Schmidt-Kloiber A, 2004. The effect of excluding taxa with low abundances or taxa with small distribution ranges on ecological assessment. Hydrobiologia 516:347-363.

Nikolaidis NP, Demetropoulou L, Froebrich J, Jacobs C, Gallart
F, Prat N, Lo Porto A, Papadoulakis V, Campana C, Skoulikidis N, Davy T, Bidoglio G, Bouraoui F, Kirkby MJ, Tournoud MG, Polesello S, González-Barberá G, Cooper D, Gomez R, Sánchez-Montoya MM, De Girolamo AM, 2013. Towards a sustainable management of Mediterranean river basins: policy recommendations on management aspects of temporary river basins. Water Policy 15:830-849.

Poos MS, Jackson DA, 2012. Addressing the removal of rare species in multivariate bioassessments: the impact of methodological choices. Ecol. Ind. 18:82-90.

Peel MC, Finlayson BL, McMahon TA, 2007. Updated world map of the Köppen-Geiger climate classification. Hydrol. Earth Syst. Sci. 4:39-473.

Prat N, 2004. El Proyecto GUADALMED. Limnetica 21:1-3.

Prat N, Gallart F, von Schiller D, Polesello S, García-Roger EM, Latron J, Rieradevall M, Llorens P, Barberá GG, Brito D, De Girolamo AM, Dieter D, Lo Porto A, Buffagni A, Erba S, Nikolaidis NP, Querner EP, Tournoud MG, Tzoraki O, Skoulikidis N, Gómez R, Sánchez-Montoya MM, Tockner K, Froebrich J, 2014. The Mirage Toolbox: An integrated assessment tool for temporary streams. River. Res. Appl. 30:1318-1334.

R Core Team, 2013. R: A language and environment for statistical computing. R Foundation for Statistical Computing, Vienna, Austria.

Resh VH, Beche LA, McElravy EP, 2005. How common are rare taxa in long-term benthic macroinvertebrate surveys? J. N. Am. Benthol. Soc. 24:976-989.

Robinson CT, Minshall GW, Royer TV, 2000. Inter-annual patterns in macroinvertebrate communities of wilderness streams in Idaho, USA. Hydrobiologia 421:187-198.

Sánchez-Montoya MM, Punti T, Suarez ML, Vidal-Abarca MR, Rieradevall M, Poquet JM, Zamora-Muñoz C, Robles S, Álvarez M, Alba-Tercedor J, Toro M, Pujante AM, Munné A, Prat N, 2007. Concordance between ecotypes and macroinvertebrate assemblages in Mediterranean streams. Freshwater Biol. 52:2240-2255.

Sánchez-Montoya MM, Vidal-Abarca M.R, Puntí T, Poquet JM, Prat N, Rieradevall M, Alba-Tercedor J, Zamora-Muñoz C, Toro M, Robles S, Álvarez M, Suárez ML, 2009. Defining criteria to select reference sites in Mediterranean streams. Hydrobiologia 619:39-54.

Sánchez-Montoya MM, Vidal-Abarca MR, Suárez ML, 2010. Comparing the sensitivity of diverse macroinvertebrate metrics to a multiple stressor gradient in Mediterranean streams and its influence on the assessment of ecological status. Ecol. Ind. 10:896-904.

Spencer M, 2000. Are predators rare? Oikos 89:115-122.

Van Sickle J, Larsen DP, Hawkins CP, 2007. Exclusion of rare taxa affects performance of the $\mathrm{O} / \mathrm{E}$ index in bioassessments. J. N. Am. Benthol. Soc. 26:319-331.

Zatovičová Z, Čiampor Jr F, Kodada J, 2004. Aquatic Coleoptera (Insecta) of streams in the Nízke Beskydy Region (Slovakia): faunistics, ecology and comparison of sampling methods. Biologia 59:181-189. 